\title{
Chiara Pagnotta, Situando los márgenes de la nación. Los italianos en ECUAdor (siglo XIX-XX). Quito: Abya-Yala, 2016, 198 pp.
}

\section{DOI: http: / / dx.doi.org/10.29078/rp.v0i48.705}

En Situando los márgenes de la nación. Los italianos en Ecuador (siglo XIX$X X)$, Chiara Pagnotta aborda la historia de la inmigración italiana en el país andino entre la Independencia y 1952. La obra está separada en cinco capítulos que abarcan, respectivamente, un período histórico particular dentro de los años mencionados. El principal objetivo que define la autora en la introducción es identificar, en una perspectiva de larga duración, el papel ideológico que ha tenido la inmigración proveniente de aquella nación latina sobre la construcción del Estado-nación ecuatoriano. Pagnotta asegura que, a pesar de que la mayoría de proyectos para atraer ciudadanos italianos al país no cuajaron debido a la falta de recursos del Estado para garantizar a los recién llegados un futuro promisorio, rastrear estos planes no concretados ofrece pistas acerca de los imaginarios de ciudadanía y de nación que se han impulsado a lo largo de los siglos XIX y XX. Argumenta, además que, si bien la inmigración italiana en Ecuador no es representativa desde un punto de vista cuantitativo, sí lo es desde una óptica cualitativa en la medida en que ha cumplido un rol significativo en la construcción de la nación. Estamos ante un libro ameno y de lectura fluida, sin embargo, a mi parecer, la historiadora no logra su cometido en tanto se salta un par de preguntas clave para demostrar la supuesta importancia ideológica de la inmigración italiana en Ecuador.

A modo de antecedentes, se narran, en el primer capítulo, las complicaciones de la época colonial para migrar hacia América desde los territorios que hoy en día conforman Italia y que, en ese entonces, estaban bajo influencia ibérica. El segundo capítulo, abarca el siglo XIX republicano, de 1830-1895, durante el cual a la inmigración europea se le otorgó una función de mejoramiento social que se apoyaba en las ideas positivistas de Auguste Comte y Herbert Spencer. Pagnotta explica que la sociedad era entendida como un cuerpo social dentro de un proceso evolutivo en el que las naciones europeas ocupaban la cúspide civilizatoria. El uso estratégico del discurso darwinista para avalar la supuesta inferioridad física y moral de la raza indígena respaldó la idea de que los indios necesitaban de la tutela europea para desarrollar plenamente su potencial humano. Pagnotta concluye que esta noción y el hecho de que las élites gubernamentales vieran a la ascendencia europea y católica como un elemento distintivo de la ecuatorianidad, se vio reflejado en su afán por promover una inmigración que cumpliera con 
estas características. Señala que el factor religioso cobró particular importancia con el ascenso de García Moreno y su proyecto de organizar el Estado ecuatoriano sobre la base de un catolicismo intransigente. Años más tarde, el progresismo para el cual el progreso era, según Pagnotta, "una ideología, un proceso y una finalidad" pretendió nuevamente estimular, por medio de la inmigración, el "blanqueamiento" de la población, considerado un sinónimo de mejora racial. Por primera vez se establecieron estructuras para impedir el arribo al país de aquellas nacionalidades consideradas nocivas y una competencia perniciosa para la inmigración deseada. Así, en 1889 se promulgó un decreto que prohibía la inmigración china, hecho que, según Pagnotta, evidencia el temor y los prejuicios de las élites hacia las clases populares. Me parece que, en este punto, hace falta evidencia explícita que respalde esta afirmación. ¿Cuál es la relación que hacen las élites políticas entre la inmigración china y las clases populares nacionales?

Las implicaciones que tuvo la Revolución Liberal sobre la inmigración italiana y los planes psrs atraerla es abordada en el tercer capítulo. La ruptura entre el Estado ecuatoriano y la Iglesia implicó la expulsión de los salesianos italianos dedicados a obras educativas y misioneras en el país. (¿Qué impacto tuvieron las misiones y enseñanzas de estos clérigos sobre la comunidad imaginada de los ecuatorianos?). Se continuó viendo con buenos ojos a la inmigración "blanca" -particularmente a aquella de los países latinos- y desdeñando a la población china y negra, así como a la peruana debido al conflicto en curso con el país vecino. El período liberal coincidió con la época de la Gran Migración en Italia que se produjo tanto por razones económicas como por exilio político y fue, según Pagnotta, una manifestación de la mundialización del mercado laboral generada por una previa movilidad de capitales. A pesar de los escasos resultados de la política pro-inmigratoria ecuatoriana, a lo largo del siglo XIX, se formó en Guayaquil una pequeña colonia italiana compuesta en su mayor parte por comerciantes provenientes de Luguria. En medio del éxito cacaotero y del surgimiento de diversas sociedades, clubes y asociaciones, surgió, en 1882, la Sociedad Garibaldi de asistencia para los italianos, con alrededor de un centenar de integrantes pertenecientes, en su mayoría, a la élite empresarial italiana. ¿Tuvo esta pequeña colonia incidencia ideológica sobre los imaginarios de ciudadanía y de nación de los guayaquileños? Pagnotta nos queda debiendo este análisis.

El cuarto capítulo versa sobre el período entreguerras en Europa que coincide con una época de depresión económica y de predominio de la oligarquía liberal en Ecuador (1912-1924). Es en esta etapa cuando las élites ecuatorianas comenzaron a pensar en un proyecto nacional-identitario capaz de integrar a las clases populares, a las poblaciones rurales y a los indígenas. Por otro lado, el ascenso del fascismo en Italia hizo que los italianos en Ecua- 
dor dejaran de ser percibidos solamente como elementos de progreso y que comenzaran a ser temidos como potenciales difusores de ideas consideradas perniciosas. Me parece que aquí cabría preguntarse cómo se concebía la ecuatorianidad frente a la alteridad fascista.

Por último, la época entre 1938 y 1952 es analizada en el quinto capítulo. Durante la Segunda Guerra Mundial, la política internacional del país se caracterizó por un rápido acercamiento político y económico a Estados Unidos y un consecuente alejamiento de las naciones europeas. ¿Qué consecuencias trajo este cambio para los imaginarios nacionales? Por esos mismos años, la Casa de la Cultura Ecuatoriana, fundada en 1944, fortaleció la oficialización de la nación mestiza como comunidad imaginada. Esto coincidió con el surgimiento de una política restrictiva frente a la inmigración y, en general, con un sentimiento en contra de los extranjeros. Especialmente, los migrantes de los países del eje fueron objeto de sospechas y represiones sin precedente. Según Pagnotta, a medidos de los años treinta y a lo largo de los años cuarenta, a la discriminación racial que había caracterizado a las políticas migratorias ecuatorianas hasta entonces, se sumó una discriminación de carácter político-ideológico. Ofrece evidencia de que por medio de trámites burocráticos se intentó dificultar soterradamente la inmigración de judíos que huían de la persecución nazi. Pagnotta aclara que si bien la presencia de los judíos italianos en Ecuador no fue relevante -solo una veintena de judíos italianos residían en el país en 1939 y se preveía la llegada de unos ochenta más-, sí lo fue en términos cualitativos, en tanto en 1922 un grupo de judíos italianos creó la sociedad Laboratorios Industriales Farmacéuticos Ecuatorianos, LIFE, que se convirtió en la industria farmacéutica ecuatoriana más importante de la época. Pero ¿tuvo esta sociedad un impacto en el proyecto de construcción nacional? Terminada la guerra, las fronteras se abrieron nuevamente. No obstante, los posteriores intentos de la Compañía Agrícola de Colonización en el Ecuador (CACE) de captar fondos para canalizar migración italiana al Ecuador no lograron su cometido, con lo que, según Pagnotta, "se cerraron prácticamente cien años en los que se había intentado, de diversas formas, la colonización del Ecuador con mano de obra italiana" (p. 175).

Pagnotta logra constatar la relación que existe entre los distintos proyectos de identidad nacional que se han desarrollado en Ecuador en el transcurso de los siglos XIX y XX, y los cambios en la política migratoria que ha impulsado el Estado con respecto a los ciudadanos italianos. Testifica la utilización oportunista que hicieron las élites ecuatorianas del siglo XIX de las teorías eugenésicas y del darwinismo social para lidiar con la cuestión indígena, mantener los privilegios heredados del Antiguo Régimen y favorecer una inmigración con la que se identificaban. Evidencia, además cuán relacionado está el tema de la identidad nacional con los fenómenos y suce- 
sos transnacionales y la historia mundial. Por último, ejemplifica cómo "el siglo XX es el momento en el que la historia se vuelve global", al señalar que Ecuador no pudo permanecer indiferente ante una guerra manejada por las potencias del hemisferio norte. No obstante, pienso que la obra de Pagnotta adolece de una confusión de enfoque y objetivos. Por un lado, la autora aspira a comprender el papel ideológico que ha tenido la inmigración italiana al interior del Estado-nación ecuatoriano, es decir, a demostrar su importancia cualitativa en los proyectos nacionales (p. 15). Argumenta que el análisis de los distintos proyectos para atraer migración italiana al país da cuenta de la concepción de nación que tenían las élites políticas de cada período a pesar de que estos planes no se hayan concretado. Se mueve, en este sentido, en el plano de los imaginarios y en el ámbito de la historia cultural. No obstante, cita a Braudel para inscribir su obra dentro de la "historia de grupos, de destinos colectivos, de movimientos de conjunto. Una historia social donde todo se mueve a partir de hombre, de los hombres, mas no de las cosas" ( $p$. 18). De hecho, gran parte del texto está dedicado a analizar la perspectiva de las autoridades italianas acerca de las posibilidades de migrar al Ecuador, la situación de los migrantes antes de partir hacia América, los puertos de embarque, la formación espontánea de redes de apoyo, los agentes migratorios, la ambivalente política migratoria del régimen fascista, etc. Si bien estos datos no dejan de ser interesantes, no aportan en nada a su objetivo inicial. Con esto no quiero decir que no se pueda combinar un enfoque de historia social sobre movimientos migratorios con uno de historia cultural. Sin embargo, al no probar la importancia cualitativa que supone ha tenido la migración italiana en la construcción del Estado-nación ecuatoriano, este cometido no se logra de manera satisfactoria.

Isabel Mena

Universidad Central del Ecuador

\author{
María Isabel Mena Mora, La baronesa de Wilson y las metáforas \\ Sobre AmÉrica y sus muJeres, 1874-1890. Serie Magíster 190, \\ Quito: Universidad Andina Simón Bolívar, Sede Ecuador / \\ Corporación EdITORA NACIONAL, 2015, 103 PP.
}

DOI: http: / / dx.doi.org/10.29078/rp.v0i48.709

Más allá de mirar a la protagonista del relato como una figura intrépida, cuya presencia femenina en la historia predisponga a un relato romántico sobre su vida, María Isabel Mena se propone escribir la trayectoria de Emilia Serrano, "la Baronesa de Wilson", desde las conexiones que generó 